\title{
THE ROLE OF THE URBAN ENVIRONMENT IN IMPLEMENTING THE CIRCULAR ECONOMY IN ROMANIA
}

\author{
Marcela-Cornelia Danu \\ "Vasile Alecsandri" University of Bacău \\ marceladanu@ub.ro \\ Elena Nechita \\ "Vasile Alecsandri" University of Bacău \\ enechita@ub.ro \\ Liliana Rozemarie Manea \\ “Gheorghe Asachi” Technical University Iasi \\ manearozemarie@yahoo.com
}

\begin{abstract}
In the present paper we analyzed the position of the Romanian urban environment in the process of implementing the circular economy, with the correlations and interdependences between the phenomena and demo-economic processes and the forms for the application of the circular economy. The poor implementation of the circular economy in the urban areas in Romania is conditioned by the low level of income, the expenditure, the consumption expenditure and the degree of low urbanization, the low level of labour productivity, etc., and by the psychology of the decision makers that is still not adjusted to the requirement to make the best choices for sustainable development of the economic system. We have highlighted the correlations between: the municipal waste recycling rate and the resource productivity in Romania; the total income of the population in the urban areas of residence in Romania and the waste recycling rate; the total average expenditure per person in urban areas and the municipal waste recycling rate; the monthly average consumption expenditure per person, in urban areas and municipal waste recycling rate; the employed population rate in urban areas and the municipal waste recycling rate; the urban population living in the 41 counties of Romania and Bucharest and the municipal waste recycling rate.
\end{abstract}

\section{Keywords}

circular economy; urban areas; income; expenditure; labour productivity; municipal waste; sustainable development of cities

\section{JEL Classification}

O13; O18; Q01; Q56; R11

\section{Strategic coordinates of the sustainable development of the cities in Romania}

In the context in which, over $3 / 4$ of the Europeans live in urban areas, the vision of the circular economy in urban areas become imperative. The productions, purchase, consumption of the inhabitants living in cities, their lifestyle have an impact on the quality of the environment (Van Kamp, 2003). More than that, the urban design and planning, the management of the territory and the urban landscape planning determine the way of living of people, their social and economic life, and, of course, the quality of the environment.

In order for a city to be durable, the decision makers must have a systemic approach, taking into account the local history context, its development over time, the current potential, and the dynamic external environment of the city, too. The targets that are set should exceed the short term border, thus they are supposed to be long-term objectives, 
with gradual stages of application in the short term: the use of renewable energy, the reduction in energy consumption per capita, the reducing of the volume of waste resulting per capita, the reduction in emissions of greenhouse gases, the sustainable use of resources, including water, land, insurance of the biodiversity space, etc. (Hoornweg, Perinaz, 2012).

Among the specific arrangements for action we can include: the production of biogas, using the organic waste as a raw material, the improving of the collection and sorting of waste, the launching of intensive information campaigns, including the educational establishments of all levels, the investment in infrastructure (i.e. specialized equipment), the energy plants, and the development of the system of relations with the civil society, public institutions, and the private sector.

Having in view the fact that the measures to be taken are supposed to meet the consumers' needs and requirements, the provision of alternative solutions and facilities, related to the choices they will make, we can conclude they are of prime importance (Blythe, 1998), (Chen, Chai, 2010). The urban inhabitants must be well informed in order to make their smart choices.

The premises of face-to-face meeting and the social networking sites must be multiplied in order to develop the system of relations, interaction, social component of the respective urban area, etc. The cultural component of the city also contributes to the achievement of this objective - the intensification of the cultural activities involving the urban inhabitants not only as consumers of cultural activities but also in their position of participants; the producers of culture having thus an important role in the valorization of the cultural-artistic potential of the citizens and, further, the diversification of their lifestyle and the improvement of the quality of the environment where the urban inhabitants live. More than that, such an attitude that is favorable to the human development determines the improvement of the city image with beneficial effects on the economic component of the latter; a city with a positive image attracts investors, new business and it strengthens the existing ones.

As a result of the poor experience, yet, in the implementation of the objectives of the sustainable human development, the decision makers of the cities in Romania will have to learn the best practices of the European cities. The key to the problem is the change of the people's mentality, both as consumers and producers, on the attitude toward the environmental issues (Stern, 1985). The role of the public authorities is threefold: to provide information, to create the necessary infrastructure, to give their personal example.

The sustainable urban development of the cities in Romania (Ginavar, 2008) is imperative under the conditions in which cities are considered to be main pawns in the competitive environment, having in view the knowledge-based on economic growth and the creation of prosperity. Bearing in mind the Lisbon Strategy, the cities in Romania must be able to answer the following questions: „How can we transpose, best of all, the European objectives, in local measures, in order that the towns to become truly competitive?”, „How can the objectives of competitiveness be achieved, providing, at the same time, the economic social territorial cohesion?”, „How can the life quality in the Romanian cities be improved?”. In the last few years, in Romania, most urban areas have been passing through the extension process, and the large urban areas have continually been subject to change. These two processes shall be conducted on the following phenomena:

- Resettlement of the population in the territory, temporary emigration with the purpose to work abroad

- Functional alterations inside the urban areas, determined by commercial buildings, headquarters of the company, collective dwellings, conversion of industrial areas or isolated industrial establishments, conversion of military 
units, building of large shops in the territory, storage facilities, private small and medium-sized firms

- A vast range of litigations that were unfortunately solved by the occupation and the dismantlement of parks and nurseries

- Development of the system of connections in the territory and in the localities which require the construction and/or the upgrading of the motorways, fast roads, highways, railways and their corresponding stations, ports of agreement, airports; the organization of the circulation in the urban areas, the reconfiguration of the sidewalks areas, etc.

At present, the cities in Romania fulfil the following roles:

- $\quad$ Provides the potential for a way of life of high quality

- $\quad$ Represents the focal point for the rising within the regions that have a large impact in the balanced regional development

- Direct and major contribution to the increasing of the competitiveness of Romania and the European Union.

The Romanian cities must comply with the Leipzig Charta on the sustainable European cities which has proposed: the strengthening of the competitiveness and of the identity of the European cities and regions, the promotion of the heritage conservation, the creation of the support EU strategy for sustainable development. The following goals are required in order to achieve the proposed objectives:

- Understanding of the importance of the sustainable urban development in the regional/national/European context

- Integrated urban planning

- Application of the urban policies, including those to thwart the climate change and to reduce risks

- $\quad$ Education and involvement of all relevant urban planning actors

- Development of partnerships

- An increase in the level of communication, of openness, of the dialog between the actors involved in urban development

- Improvement of the quality of public services

- Improvement of the accessibility and mobility by creating and/or upgrading of infrastructure, parking areas, public spaces

- $\quad$ Regeneration of the local identity, changing of mentalities

- New practices in the public administration.

\section{Aspects of implementing the circular economy}

An important aspect which the concept of circular economy highlights (EAA, 2015) is the non-inclusion within the production costs of the pollution costs generated by production and consumption; that is to say, the negative externalities. The negative externalities of the firms can be found only in the calculation of their social costs and not in their private costs that is in fact the basis for the calculation of the firm profits. Therefore, none of the products available on the market do not reflect the real costs of that product. The services that nature provides to us are not reflected in the economic situation of the firms. One reason is the difficulty of assessing the accuracy of all adverse effects and of their size both in the short term and in the medium and long term. It is also difficult to identify all the involved entities, all the more so, the risks rage to which we are exposed is highly diversified and for accurate capturing of these it is necessary the collaboration of several centers for analysis and evaluation. So, to approach the issue of negative externalities only through the inclusion in the firm costs of some estimated expenses it is at least incorrectly both for the environment coordinates as well as for the individuals (De Oliveira, Puppim et al, 2013). More than 
that, an important element of the triad the „consumer-firm-environment”, (Danu, 2001), that is, the firm will be affected; in the case in which the identification and the correct assessment of all the adverse effects that are caused to the consumer and to the environment will be successful, the firm will not be able to cope with the very huge costs but only by including them into their costs and, further, in the production price of their outputs. If this is the case, in the end, on the one hand, the consumer will have to pay by the price at which they will purchase the product and, on the other hand, the firm that will add these costs, too, will lose some of the volume of its sales in favour of those firms that will focus on the basis of the demand and not on a cost-oriented basis. It is a vicious circle in which, for the time being, there is no way out. One solution would probably be the reconsideration of all the types of expenses, of their level, including the relations between their levels, as well.

From the point of view of the consumer, the issue that is involved refers to the level of acceptability of a price higher than the consumer would have to pay for the goods which include the negative externalities of the firm in relation with the environment (Kirchoff et al, 2011). In addition, urban areas with a high density of population and with a high degree of concentration of economic activities (more or less polluting) are, on the one hand, put to advantage by the potential of a high quality of life, and, on the other hand, are inherently exposed, not only to natural risks (mainly pollution) but also taking responsibility for higher levels of the prices of tangible and intangible goods. The costs involving the exposure of the population to natural hazards - diseases that may occur, their effects in time, etc., are difficult to estimate with accuracy, in order to be included in their calculation of the costs by the accountants of the firms. An approximate solution is already used in some countries of the world: the establishment of some environmental taxes. The optimum choice seems to be the subsidizing by the government of these costs in order not to damage the standard of living of the population who buy products at a price which includes these charges. On the other hand, the government subsidizing of such charges without the permanent government monitor and without the government penalization when the firms and the population fail to follow the natural environment would cause financial losses to the government budget and, possibly, the increase in the government public debt. In the event that the government subsidizing for the environment taxes shall be applied (the sales prices of the products are smaller) the population would have to choose those products that are less harmful to the environment but, the condition is that, in the perception of the consumer the lower price of the product might not be associated with other reasons such as: promotional techniques, poor quality of the product, hidden vices, etc. To prevent such consumer behaviours, a permanent and sustained communication with consumers is necessary; the government and economic agents that are producers or traders need to inform, to persuade and remind the consumers the price facility they are offered and the need of buying sustainable products and services. Even so, there is a financial risk the government entity may incur. On the other hand, in case of lack of communication or poor communication with consumers, the manufacturing firm undertakes a risk of image and the consumers, in their turn, incur the psycho-social risks, as determined by the purchasing which cannot meet their expectations (Peptenatu et al, 2011); the need to change their lifestyle, usage patterns, etc., are also supposed.

\section{Correlations and interdependences within the circular economy}

An essential objective of the economic development of a country is the increase of the productivity of all production factors; the circular economy is ensured but by increasing the productivity of the production factors attached to the environment - the raw materials, fuels, and energy (Barbier, 2011). In Table 1 we have highlighted the municipal waste recycling rate and the resource productivity in Romania in the period 
2003-2011. We notice that, up to the year 2005, the municipal waste recycling rate increased from $0.29 \%$ to $2.22 \%$, followed by a regression in 2006 after which, even in conditions of economic crisis, it increased at a high pace reaching to $7 \%$ in the year 2011. The resource productivity had, however, an inverse evolution, starting from 0.90 thousand Lei/ton in the year 2003, 0.91 thousand Lei/ton in the year 2004 after which, a sinusoidal evolution but without any return to the level reached in 2004. What can be said under these conditions? The evolution of the Romanian economy, mainly of the industry, was marked by a negative dynamic in terms of productivity of the production factors that are detached from the environment. The confirmation of this situation is given by the Pearson correlation coefficient (Drugan, 2005), (Cătoiu, 1999), with the help of which we have tried to observe if there is any correlation and intensity level between the municipal waste recycling rate (x) and the resource productivity (y) (see Table 1), in Romania, in the period 2003-2011.

Table 1 Municipal waste recycling rate and resource productivity, in Romania

\begin{tabular}{|c|c|c|}
\hline Years & $\begin{array}{c}\text { Municipal waste } \\
\text { recycling rate (\%) }\end{array}$ & $\begin{array}{c}\text { Resource } \\
\text { productivity } \\
\text { (Thousands lei/tonne) }\end{array}$ \\
\hline 2003 & 0,29 & 0,90 \\
\hline 2004 & 1,39 & 0,91 \\
\hline 2005 & 2,22 & 0,87 \\
\hline 2006 & 0,65 & 0,87 \\
\hline 2007 & 1,06 & 0,78 \\
\hline 2008 & 1,10 & 0,66 \\
\hline 2009 & 2,00 & 0,78 \\
\hline 2010 & 6,00 & 0,84 \\
\hline 2011 & 7,00 & 0,75 \\
\hline
\end{tabular}

By applying the formula the Pearson correlation coefficient $(n=9)$ we get the $r=-0.2084$ so, between the two indicators there is an inverse relationship of low intensity.

$$
\frac{n \sum x y-\sum x \sum y}{\sqrt{\left.\left[n \sum x^{2}-\left(\sum x\right)^{2}\right] n \sum y^{2}-\left(\sum y\right)^{2}\right]}}
$$

Of course, a resource productivity as high as possible can result in the saving of resources, and in a lower level of collected waste; and thus the waste recycling rate in the urban areas will be less. It is somewhat paradoxical the intensity of correlation between the two variables because, within an efficient economy, with high levels of productivity of the production factors, the positive propagation on the economy of waste is obvious. The explanation lies in the large difference between Romania and the EU developed countries, as regards the levels of productivity of all production factors and the decrease of the resource productivity after the year 2003.

Having in view the fact that the obtaining of waste has as a premise the individual decisions of the exponents of the demand and supply in question, as well as the consumers and the producers we have first analyzed the impact of the consumer behavior involving their decision-making; the decision of consumption and, in the end, the accumulation of waste, have as a prerequisite the people's income. It is to be noted that, although the crisis had negative effects on the economic development in Romania, 
the level of the monthly average income of the urban population has increased. Having a sinusoidal evolution of the municipal waste recycling rate, though very low at the beginning of the period, began to strongly grow after 2009, showing a new and intelligent attitude of the urban decision makers in relation with the environment.

In Table 2 we have shown the evolution of the total income of the urban population in Romania average of total income per person, in urban area $(\mathrm{x})$ and the municipal waste recycling rate (y) in the period 2003-2011. We have calculated the correlation between the two indicators, the coefficient of correlation $(r=0.6508)$, expressing that between the two indicators there is a direct correlation, of medium intensity, justified by the direct link between the income and the consumption, and its finality respectively, the externalization of the consumption.

Table 2 Economic and environmental indicators, in Romania, 2003-2011

\begin{tabular}{|c|c|c|c|c|c|}
\hline Year & $\begin{array}{c}\text { Monthly averages } \\
\text { of total income } \\
\text { per person, } \\
\text { in urban area } \\
\text { (lei) }\end{array}$ & $\begin{array}{c}\text { Monthly } \\
\text { averages } \\
\text { of total } \\
\text { expenditure per } \\
\text { person, in urban } \\
\text { area (lei) }\end{array}$ & $\begin{array}{c}\text { Average } \\
\text { consumption } \\
\text { expenditure } \\
\text { per capita, } \\
\text { in urban area } \\
\text { (lei) }\end{array}$ & $\begin{array}{c}\text { Employment } \\
\text { rate in urban } \\
\text { area (\%) }\end{array}$ & $\begin{array}{c}\text { Municipal } \\
\text { waste } \\
\text { recycling } \\
\text { rate (\%) }\end{array}$ \\
\hline 2003 & 317,23 & 310,07 & 212,42 & 47,5 & 0,29 \\
\hline 2004 & 403,53 & 386,17 & 263,46 & 48,9 & 1,39 \\
\hline 2005 & 472,67 & 441,80 & 310.38 & 47,9 & 2,22 \\
\hline 2006 & 552,97 & 511,99 & 357.78 & 49,8 & 0,65 \\
\hline 2007 & 669,17 & 606,28 & 413.48 & 49,5 & 1,06 \\
\hline 2008 & 855,34 & 756,09 & 514.40 & 49,9 & 1,10 \\
\hline 2009 & 928,80 & 806,33 & 549.90 & 49,4 & 2,00 \\
\hline 2010 & 925,92 & 811,85 & 552.56 & 49,5 & 6,00 \\
\hline 2011 & 946,98 & 835,43 & 566,25 & 50,2 & 7,00 \\
\hline
\end{tabular}

Source: $\underline{w w w . i n s s e . r o}$

In the case of the total average expenditures per person in urban areas average of total expenditure per person, in urban area, in the period under consideration (see Table 2), we notice that the effects of the economic and financial crisis did not reflect in their dynamic only by the temporization of the increase of expenditures; the correlation between the total average expenses per person in urban areas average of total expenditure per person, in urban area (x) and the municipal waste recycling rate (y), in the period 2003-2011; $r=0.6556$ shows the direct link, of medium intensity, between these indicators. As we mentioned earlier, the size and the intensity of the correlation between the variables that shape the economic situation of the societal entities (firms, consumers, government and buying decisions, consumption, post-consumption) shall designate the level of relations with the environment.

Being an important component of the average of total expenditure, the average consumption expenditure per person in urban areas (see Table 2) have recorded an increasing evolution, even if the impact of the crisis diminished their increase rate in the period in some respects 2003-2011. The correlation between the average consumption expenditure per person in urban areas $(\mathrm{x})$ and the municipal waste recycling rate $(y)$, that is, $r=0.6525$, confirm the direct correlation of medium intensity between the two variables but also the development in the direct proportion of indicators: the average of total income per person, in urban area/ the average of total expenditure per person, in urban area/ the average consumption per person, in urban area and municipal waste recycling rate. We consider that an increase of the intensity 
of these correlations highlights a high potential for the valorizing of the consumption externalities that is still unexploited. Therefore the development of the circular economy at the level of urban entities has strong conditions to be used.

If in the period 2003 - 2011 Romania's population evolved in a negative direction dropping from 21,627,509 inhabitants to 20,199,059 inhabitants (decrease by 6.6\%) while the urban population dropped from 11,434,118 inhabitants to 10,902,302 inhabitants (drop of 4.65\%). The weighting of residential population in urban areas increased up to the year 2007 (from 52.86\% in 2003 to $55.44 \%$ in 2007) and then it dropped to 53.97\% in 2011 and 53.89\% in 2014. The employment rate in urban area followed a relatively good evolution, increasing from $47.5 \%$ in 2003 to $50.25 \%$ in 2011 and $50.4 \%$ in the second semester of the year 2014. The increase is mostly determined by the decrease in share of urban population within the total population and, further, within Romania's population in the last few years. Under these circumstances, while correlating the employment rate in urban area $(x)$ with the municipal waste recycling rate (y) in the period 2003 - 2011 (see Table 2) a direct correlation $(r=0.4168)$ with an acceptable degree of association may result. From the point of view correlation direction, there is a noticeable direct link between the population providing different types of economic activities, being involved in carrying out the outputs (positive or negative for the societal life) and implicitly of the waste but the rate of reuse, recovery, reintegration of waste in the production cycle is also determined by the weighting and actions of the unemployed population within the total urban population (Barbier, 2010). With regard to the correlation between the urban population for the 41 counties and Bucharest, too (the urban population of the county related to the urban population of Romania) and the municipal waste recycling rate in the 41 counties (calculated as the ratio in percentage terms between the recycled waste and collected waste, at county level) in 2011 (the last year with available information on www.insse.ro) we have presented (see Table 3) the two analyzed indicators; we have used the method of the Spearman rank correlation to highlight the correlation between the two variables (the demographic one and economic one) that has an impact on the natural environment in the long term.

\section{Table 3 Correlation between urban population and municipal waste recycling} rate in Romania, 2011

\begin{tabular}{|c|c|c|c|c|}
\hline County & $\begin{array}{c}\text { County urban population/ } \\
\text { Romania's urban } \\
\text { population (\%) }\end{array}$ & Rank & $\begin{array}{c}\text { Municipal waste } \\
\text { recycling rate * } \\
\text { (\%) }\end{array}$ & Rank \\
\hline Alba & 1,82 & 21 & 1,11 & 29 \\
\hline Arad & 2,15 & 18 & 0,46 & 38 \\
\hline Argeș & 2,55 & 13 & 2,36 & 25 \\
\hline Bacău & 2,81 & 11 & 5,84 & 14 \\
\hline Bihor & 2,55 & 14 & 15,39 & 5 \\
\hline Bistrița-Năsăud & 1,00 & 38 & 1,4 & 28 \\
\hline Botoșani & 1,59 & 24 & 9,98 & 9 \\
\hline Brăila & 1,92 & 19 & 0,14 & 40 \\
\hline Brașov & 3,67 & 4 & 1,96 & 26 \\
\hline Buzău & 1,66 & 22 & 0,09 & 42 \\
\hline Călărași & 1,03 & 37 & 15,84 & 4 \\
\hline Caraș-Severin & 1,58 & 25 & 0,97 & 32 \\
\hline
\end{tabular}




\begin{tabular}{|c|c|c|c|c|}
\hline Cluj & 3,78 & 3 & 3,03 & 22 \\
\hline Constanța & 4,27 & 2 & 0,92 & 33 \\
\hline Covasna & 0,93 & 40 & 5,63 & 15 \\
\hline Dâmbovița & 1,38 & 30 & 0,92 & 34 \\
\hline Dolj & 3,11 & 8 & 0,11 & 41 \\
\hline Galați & 2,88 & 10 & 1,81 & 27 \\
\hline Giurgiu & 0,73 & 42 & 7,89 & 10 \\
\hline Gorj & 1,44 & 29 & 0,81 & 35 \\
\hline Harghita & 1,18 & 32 & 2,76 & 23 \\
\hline Hunedoara & 3,00 & 9 & 14,23 & 6 \\
\hline Ialomița & 1,12 & 36 & 5,48 & 16 \\
\hline Iași & 3,28 & 7 & 1,04 & 30 \\
\hline Ilfov & 1,12 & 35 & 0,47 & 37 \\
\hline Maramureș & 2,53 & 15 & 3,22 & 20 \\
\hline Mehedinți & 1,19 & 31 & 0,36 & 39 \\
\hline Mureș & 2,52 & 16 & 14,19 & 7 \\
\hline Neamț & 1,84 & 20 & 6,47 & 12 \\
\hline Olt & 1,60 & 23 & 3,73 & 18 \\
\hline Prahova & 3,35 & 6 & 1,02 & 31 \\
\hline Sălaj & 0,85 & 41 & 11,42 & 8 \\
\hline Satu Mare & 1,52 & 28 & 3,13 & 21 \\
\hline Sibiu & 2,47 & 17 & 3,34 & 19 \\
\hline Suceava & 2,55 & 12 & 6,02 & 13 \\
\hline Teleorman & 1,17 & 34 & 0,6 & 36 \\
\hline Timiş & 3,59 & 5 & 81,12 & 1 \\
\hline Tulcea & 0,98 & 39 & 34,38 & 2 \\
\hline Vâlcea & 1,55 & 27 & 23,51 & 3 \\
\hline Vaslui & 1,57 & 26 & 7,56 & 11 \\
\hline Vrancea & 1,18 & 33 & 2,64 & 24 \\
\hline București & 16,98 & 1 & 5,01 & 17 \\
\hline
\end{tabular}

Source: Processed from www.insse.ro

Having in view the fact that the sample size is $>10$, the Spearman statistical test is $\mathrm{Z}=\frac{6 \mathrm{R}-\mathrm{n}\left(\mathrm{n}^{2}-1\right)}{\mathrm{n}(\mathrm{n}+1) \sqrt{\mathrm{n}-1}}$ where $\mathrm{R}=\sum_{\mathrm{i}=1}^{\mathrm{n}} d_{i}^{2}$ and it can be compared with the critical value of the normal distribution table.

The obtained value for $\mathrm{Z}$ is 0.5826 so between the two indicators there is a direct connection of medium intensity. We test the significance of the correlation coefficient of the ranks by comparing its value with the reference value for the level of significance of 0.05 (from the table). We observe that the value of $\mathrm{Z}$ is $0.5828>0.313$ so we reject the zero hypothesis according to which there is no correlation between the two variables. Given the fact that the dimension of the sample is high we can use the test $t$ 
by applying the formula $\mathrm{t}=\mathrm{Z} \cdot \sqrt{\frac{\mathrm{n}-2}{1-\mathrm{Z}^{2}}}$ to test the significance of the correlation coefficient.

In accordance with the table t, the reference value for the level of significance is 0.05 $=0.684$, having in view the bi-directional assumption. The obtained value for the $t$ (in our case) is 2.994 so $>0.684$. It is accepted the alternative hypothesis according to which there is a direct correlation between the two variables.

In conclusion, by analyzing the connections between several variables that are specific to the economic environment and the demographic environment, on the one hand, and the municipal waste recycling rate, as a significant indicator for the implementation of the circular economy, on the other hand, we notice the existence of the correlations where the medium or acceptable intensity of these highlights the potential of the Romanian economy in the field of waste reintroduction in the economic circuit.

\section{Conclusion}

The circular economy focuses on the consumer thus understanding that ,there is no business without customers” and that „the goal of business means the customer base development as well as the customer fidelity" and it surpasses this vision by integrating the management of the relation with the natural environment within the equation of company success (Peattie, Belz, 2010). The multiplication, diversification and strengthening of the relationships downstream a company (with the customers of products that are modernized, adapted or new because of the circular economy implementation but with other entities, too) are based on a new philosophy and action concerning information and communication meant to be permanent and effective (EIU, 2005).

In the EU circular economy is a policy procedure in advanced application and the differences between the levels of development of the European actors reveal different stages of this process. In Romania even though the environment protection, in a general sense, and the environment protection in urban areas, as a specific purpose, have started to be a constant preoccupation for the decision makers in the firms and public administration, the context: that is, the demographic one, the economic one, the technological one and last but not least, the cultural one that is insufficiently trained (the low income level, expenditures, consumption expenditure in urban areas, average rate of low urbanization and large discrepancies between the 41 counties, inappropriate mentality to the new trends, etc.) determines small rates of waste collection, small rates of waste recycling, options that are still limited toward implementing the circular economy.

\section{References}

Barbier, E.B. (2010), Poverty, development, and environment, Environment and Development Economics, pp 635-660, available at http:// journals.cambridge.org/action/.

Barbier, E.B. (2011), The policy challenges for green economy and sustainable economic development, Natural Resources Forum, 35: 233-245, http://onlinelibrary.wiley.com/.

Blythe, J. (1998), Consumer behavior, strategies and tactics, Attract customers, consumer reaction, Bucharest, Teora, pp 226-227.

Cătoiu, I., Bălan, C., Onete, B., Popescu, I., Vegheş, C. (1999), Methods and Techniques Used in Marketing Research; practical applications, Bucharest, pp 209-214. 
Chen, T.B., Chai, L.T. (2010), Attitude towards the Environment and Green Products: Consumers' Perspective, Management Science and Engineering Vol. 4, No. 2, pp. 27-39, available at http://www.cscanada.net/ index.php/mse/ article/.

Danu, M. C.(2001), Business Risks, Bacău, Plumb.

De Oliveira, J.A., Puppim, D., Christopher N.H., Balaban, O, Jiang, P., Dreyfus, M.S, Aki, Moreno-Peñaranda, Raquel, D.P. (2013), Green economy and governance in cities: assessing good governance in key urban economic processes, Journal of Cleaner Production, pp 138-152, available at http://www.sciencedirect.com/ science/journal/.

Drugan, T., Achimaş, A., Tigan, S. (2005), Biostatistics, Bucharest, Srima, pp 266-268.

EAA (2015), The Well-being and the Environment - creating a circular economy that is effective from the point of view of resources utilization in Europe, available at http://www.eea.europa.eu/.

Ginavar, A. (2008), Sustainable urban development - challenges for Romania cities available at www.mdlpl.ro.

Global e-Sustainability Initiative (2014), SMART 2020: Enabling the low carbon economy in the information age, available at http://gesi.org.

Hoornweg, D., Bhada-Tata, P., What a Waste: A Global Review of Solid Waste Management, WB, available at https://www.openknowledge.worldbank.org/.

Kirchoff, J.F., Koch, C., Satinover N., Bridget. (2011), Stakeholder perceptions of green marketing: the effect of demand and supply integration, International Journal of Physical Distribution \& Logistics Management, Vol. 41 Iss: 7, pp.684 - 696, available at http://www.emeraldinsight.com/.

Krugman, P. (2010), Building a Green Economy, The New York Times, available at http://www.nytimes.com/.

Mori, K., Christodoulou, A. (2011), Review of sustainability indices and indicators: Towards a new City Sustainability Index (CSI), Environmental Impact Assessment Review, available at http://www.sciencedirect.com/ science/article/.

National Institute of Statistics (2014), Bacău, available at http://www.bacau.insse.ro/.

Peattie, K., Belz, F.M. (2010), Sustainability Marketing: An Innovative Conception of Marketing, Marketing Review, St. Gallen 5, Vol. 27, Issue 5, pp 8-15.

Peptenatu, D., Pintilii R.D., Draghici C. (2011), Environmental risk management of urban growth poles regarding national importance, International Journal of Environmental Science \& Technology, Vol 8, Issue 4, pp 737-746, available at https://tspace.library.utoronto.ca/bitstream/1807/62961/1/.

Perrings, Ch., Duraiappah, A., Larigauderie, A., Mooney, H. (2011), The Biodiversity and Ecosystem, Services Science-Policy Interface, Vol. 331 no. 6021 pp. 11391140, available at www.sciencemag.org.

Stern, P.C., Dietz, Th., Black, J.S. (1985), Support for environmental protection: The role of moral norms, Population and Environment, Volume 8, Issue 3-4, pp 204222.

The Economist Intelligence Unit, The Economist Intelligence Unit's quality-of-life index (2005), available at http://www.economist.com/media/ pdf/ Quality_of_Life.

Van Kamp, I., Leidelmeijer, K., Marsman, G. \& De Hollander, A. (2003), Urban environmental quality and human well-being. Towards a conceptual framework and demarcation of concepts; a literature study, Landscape and Urban Planning, 65, pp 5-18. 